\title{
Avaliação do uso do solo e dos recursos florestais no semiárido do estado da Paraíba
}

\author{
Evaluation of land use and forest resources in the semiarid of Paraíba state
}

\author{
Luiz Moreira Coelho Junior ${ }^{\mathrm{I}}$, Mariane Gama de Medeiros ${ }^{\mathrm{II}}$, \\ Anna Manuella Melo Nunes ${ }^{I I I}$, Milca Laís da Luz Macieira ${ }^{\mathrm{IV}}$, \\ Márcia Batista da Fonsecav
}

\begin{abstract}
Resumo
Avaliou-se o uso do solo e dos recursos florestais do bioma Caatinga no estado da Paraíba, de 1996 a 2018. Foram levantados dados da cobertura vegetal e das características dos recursos florestais e o seu potencial produtivo para a lenha e o carvão vegetal. As informações empregadas para caracterização do uso do solo e dos recursos florestais da Paraíba foram obtidas do Instituto Brasileiro de Geografia e Estatística (IBGE), do Ministério do Meio Ambiente (MMA) e da Associação Plantas do Nordeste (APNE). A pesquisa foi exploratória e os resultados apontam a existência de uma degradação contínua da cobertura vegetal, porém os tipos de uso do solo se modificaram ao longo dos anos estudados. Observou-se uma alteração no uso das terras da Paraíba com uma ampliação das áreas de matas/florestas e redução das áreas de pastagem. O carvão vegetal e a lenha foram os principais produtos do extrativismo. A Caatinga paraibana perdeu mais de $46 \%$ da sua vegetação, cerca de 2,40 milhões de hectares, mas observou-se o aumento do PMFS via adoção de políticas públicas e conscientização do mercado. As estimativas adotadas da cobertura vegetal e do uso do solo da Paraíba mostraram sensibilidade e elevado grau de risco à desertificação do bioma, necessitando de ações conjuntas permanentes que garantam o uso sustentável da biodiversidade. Concluise que a solução efetiva vem da conscientização e da prática do Plano de Manejo Florestal Sustentado no semiárido paraibano, proporcionando de forma mais eficaz a sustentabilidade do bioma Caatinga.
\end{abstract}

Palavras-chave: Caatinga; Manejo florestal; Bioenergia

\begin{abstract}
The use of soil and forest resources of the Caatinga biome in the state of Paraibawas evaluated from 1996 to 2018. Data on vegetation cover and forest resource characteristics and their productive potential for firewood and charcoal were collected.The information used to characterize Paraíba's land use and forest resources were examined by the Brazilian Institute of Geography and Statistics (IBGE), the Ministry of Environment of Brazilian (MMA) and the Northeast Plants Association (APNE). The research is exploratory and based on secondary data and may contribute, in part, to the economic development in the state. The results point to the existence of a constant degradation of the vegetation cover, although the types of soil use have changed over the studied years. The estimates adopted for vegetation cover and land use in Paraíba showed sensitivity and a high degree of risk to desertification of the biome, requiring permanent joint actions that guarantee the sustainable use of its biodiversity. It is concluded that the effective solution comes from the awareness and the practice of the Sustainable Forest Management Plan in the semi-arid region of Paraíba, providing more effectively the sustainability of the Caatinga biome.
\end{abstract}

Keywords: Caatinga; Forest management; Bioenergy

Economista, Dr., Professor do Departamento de Engenharia de Energias Renováveis, Universidade Federal da Paraíba, Caixa Postal 5115, CEP 58051-900, João Pessoa (PB), Brasil. luiz@cear.ufpb.br (ORCID: 0000-0001-5528-7799)

Engenheira Ambiental, Mestre pelo Programa de Pós-Graduação em Energias Renováveis da Universidade Federal da Paraíba, Caixa Postal 5115, CEP 58051-900, João Pessoa (PB), Brasil. marianegm@bol.com.br (ORCID: 0000-0002-7426-7205)

III Advogada, Mestranda do Programa de Pós-Graduação em Energias Renováveis da Universidade Federal da Paraíba, Caixa Postal 5115, CEP 58051900, João Pessoa (PB), Brasil. annamanuellam@gmail.com (ORCID: 0000-0002-2762-9330)

Ecóloga, Mestranda do Programa de Pós-Graduação em Energias Renováveis da Universidade Federal da Paraíba, Caixa Postal 5115, CEP 58051900, João Pessoa (PB), Brasil. milca18.macieira@hotmail.com (ORCID: 0000-0002-8119-8842)

Economista, Dr ${ }^{a}$., Professora do Departamento de Economia, Universidade Federal da Paraíba, Caixa Postal 5115, CEP 58051-900, João Pessoa (PB), Brasil. mbf.marcia@gmail.com (ORCID: 0000-0002-0937-2172) 


\section{Introdução}

O uso de produtos florestais atende as demandas da sociedade e o seu impacto sobre a conservação é uma preocupação global. A atenção mundial está voltada à preservação das florestas tropicais húmidas, devido às grandes reservas de madeira e de carbono. As regiões semiáridas e áridas se destacam pela densidade populacional e consequente intensidade do uso dos recursos florestais (MELO, 2004; COELHO JUNIOR; MARTINS; SILVA, 2018).

Para Shumacher e Poggiani (1993), no Brasil, a formação de maciços florestais por espécies exóticas é consequência da demanda industrial doméstica. A atividade florestal no semiárido brasileiro tem importância econômica, principalmente, como insumo energético, em que é a segunda fonte mais utilizada na matriz energética da maioria dos estados dessa região (COELHO JUNIOR, MARTINS; CARVALHO, 2018). Melo (2004) relatou que mais de 18 milhões de pessoas povoam o semiárido nordestino, sendo favorecidas direta ou indiretamente pelo uso dos recursos naturais da região que acontece, em grande parte, de forma não-sustentável (BARBOSA et al., 2005). A dificuldade de uma alternativa de renda para os agricultores transforma o desenvolvimento de atividades sustentáveis, em uma ferramenta para favorecer a fixação do homem no campo e a predominância de uma sobrevivência justa (MARTINS et al., 2018; SILVA; SOARES; PAREYN, 2008).

Em função das condições socioeconômicas na região do semiárido brasileiro, foram incorporadas as atividades agropecuárias. Essa ocupação ocorreu desordenadamente, sem a preocupação com a biodiversidade e os recursos naturais (SILVA; SOARES; PAREYN, 2008). Giulietti et al. (2004) afirmam que a agricultura, a criação de pastagens e o extrativismo vegetal, para lenha, carvão, entre outras maneiras de proveito da flora nativa, vêm ocasionando inúmeras perdas de biodiversidade no bioma Caatinga. Castelletti et al. (2004) verificaram que mais de $330 \mathrm{mil} \mathrm{km} \mathrm{km}^{2}$ já foram alterados pelo homem, o correspondente a $45 \%$ do domínio do bioma. Os produtores e as empresas dispostos a investir na região têm buscado alternativas que harmonizem o aumento da produtividade, a redução dos custos de produção e a conservação da biodiversidade (GIULIETTI et al., 2004).

A Caatinga é um agrupamento de tipos de vegetação com certas características em comum, determinadas, sobretudo, pela forte condição de estacionalidade das chuvas na região semiárida, aglomeradas em curto período do ano. O Brasil possui, aproximadamente, uma extensão de $735.000 \mathrm{~km}^{2}$ do bioma Caatinga. A vegetação retrata os fatores climáticos relevantes do semiárido e estes indicam os tipos de solo, o relevo e as redes hidrográficas da região. A soma desses fatores resulta em tipos de vegetação xerofítica muito especial, particular das paisagens do nordeste brasileiro. A Caatinga abrange aproximadamente $55 \%$ dos $1.548 .672 \mathrm{~km}^{2}$ da área da região Nordeste. A grande variedade dos tipos de clima, de solo e das formas de relevo se manifesta em distintas paisagens do semiárido, como os vales úmidos, as chapadas sedimentares e as amplas superfícies pediplanadas, justificando a presença de flora tão variada. A Caatinga, também, possui um sistema de chuvas extremamente irregular de ano para ano, o que resulta em secas severas periódicas. Esses fatores climáticos colaboram para a deterioração dos solos e da vegetação nativa, porém a modificação da paisagem decorre da antropização do ambiente, por meio da supressão dos recursos naturais via extrativismo vegetal (ex. exploração de lenha), agropecuária, criação e expansão urbana. Esses elementos tornam essa região em áreas sensíveis e aceleram o processo de desertificação (GIULIETTI et al., 2004; IBGE, 2004; 2016).

O estado da Paraíba está localizado na região Nordeste do Brasil, com uma área de $56.468,435 \mathrm{~km}^{2}$ e população de 3.999 .415 habitantes. O bioma Caatinga possui cerca de $90 \%$ da cobertura vegetal e, em termos relativos, é o maior estado de abrangência territorial. A lenha foi a principal fonte, participando com $41 \%$ da matriz energética estadual, e correspondeu aproximadamente $25 \%$ do abastecimento energético industrial paraibano. Isso se deve pela cobertura florestal existente, que apesar da baixa participação ao comparar com outros estados $(23,25 \%)$, possui suma importância na atividade florestal regional. Esses fatores socioeconômicos 
ligados às condições naturais da Caatinga, possibilitam a prática do manejo florestal como: alta capacidade de rebrota e ciclo de corte relativamente pequeno (IBGE, 2016; LEAL et al., 2005).

O principal desafio a ser enfrentado no bioma é a pobreza instalada na Caatinga, deixando a preservação e a conservação da biodiversidade em menor prioridade. Uma forma de garantir a exploração sustentável do extrativismo vegetal é por meio do manejo florestal. Essa técnica consiste em adotar ações que garantam uma produção economicamente viável, por meio de medidas socioambientais, em todas as fases do projeto. O uso do Plano de Manejo Florestal Sustentado (PMFS) tornou-se uma alternativa frente ao desmatamento ilegal e descontrolado e proporciona a regeneração das áreas degradadas, além da geração de emprego e renda. $\mathrm{O}$ PMFS tornou-se uma forma eficiente de garantir a biodiversidade da região, bem como um investimento rentável, mitigando impactos ambientais e trazendo efeitos positivos no âmbito social, econômico e florestal (AHRENS, 2005; IBGE, 2016).

Leal et al. (2005) afirmaram que o uso sustentável da biodiversidade da Caatinga garante recursos para minimizar a pobreza da região. Os desequilíbrios ecológicos e sociais decorrentes dessa conjuntura retratam a peleja atual da preservação e conservação do PMFS, gerando possibilidades socialmente justa. Na Paraíba, além de ocasionar graves perdas de biodiversidade, essa maneira de consumo exacerbado dos recursos naturais, tem acelerado o processo de desertificação. Os estabelecimentos rurais e florestas são propriedade de direito privado. Logo, os PFMS sujeitam-se às iniciativas individuais e de encorajamentos ou desencorajamentos governamentais (BRASIL, 2004).

Gariglio e Barcellos (2010) e Riegelhaupt e Pareyn (2010) discutiram a importância do manejo florestal no bioma Caatinga. Porém, dentre esses estudos, o conceito de uma atividade florestal sustentável ainda é recente, e muitos não consideram a técnica de manejo florestal para produção florestal no semiárido, especificamente. Dessa forma, analisar, no estado da Paraíba, o uso de florestas nativas para geração de energia, com o emprego de técnicas de sustentabilidade, é um estudo inovador. Logo, neste estudo avaliou-se o uso do solo e dos recursos florestais do bioma Caatinga no estado da Paraíba.

\section{Materiais e métodos}

Esta pesquisa foi exploratória e descritiva, realizada a partir de dados secundários obtidos de referências bibliográficas e documentais, tendo como fontes principais: o Censo Agropecuário (1996, 2006 e 2017) e estatísticas do IBGE, o banco de dados da Associação Plantas do Nordeste (APNE), do Ministério do Meio Ambiente (MMA) e da Rede de Manejo Florestal da Caatinga (RMFC), que foram construídos a partir de informação coletada nas instituições ambientais do Nordeste.

O objeto de estudo foi o estado da Paraíba com ênfase na participação do bioma Caatinga no estado, no período de 1995 a 2018. Levantou informações a respeito da cobertura vegetal e uso do solo no semiárido paraibano, assim como os tipos de uso do solo, sua área e participação geográfica dentro da região. Verificou-se a distribuição dos estabelecimentos agropecuários e as principais atividades econômicas, agropecuárias ou florestais, a fim de entender a evolução da supressão vegetal. Para efeito de comparação das áreas desmatadas com as áreas ainda inexploradas, foi realizado o levantamento das áreas remanescentes florestais, sejam elas de áreas de proteção ambiental (Unidades de Conservação) ou áreas ainda não antropizadas.

No segundo ponto foram discutidas as quantidades das principais produções florestais da região e sua área de abrangência, fazendo uma relação com dados observados da área total de Planos de Manejo Florestal Sustentado (PMFS) ativos no estado. Por fim, foi realizada uma análise integrada de toda a situação e o uso de recursos florestais no semiárido do estado. 


\section{Resultados e discussão}

\section{A cobertura vegetal e o uso do solo paraibano}

$\mathrm{Na}$ Tabela 1, observam-se áreas das grandes unidades de paisagem que primitivamente incluíam vegetação de Caatinga na Paraíba. Giulietti et al. (2002) mostraram que a área de Caatinga na Paraíba foi $49.000 \mathrm{~km}^{2}$. As informações e dados referentes à cobertura vegetal da Caatinga na Paraíba são escassas e aquelas disponibilizadas pelos órgãos governamentais competentes encontram-se desatualizadas. A maior unidade de paisagem se encontra na Depressão Sertaneja $(49,96 \%)$ e vem apresentando sinais de desertificação, reforçados pela exploração da lenha de forma desordenada e exacerbada. O segundo lugar esteve o Planalto da Borborema $(25,3 \%)$ e a terceira colocação os Maciços e Serras Baixas (14,08\%).

Segundo o Ministério do Meio Ambiente - MMA (BRASIL, 2011), a situação do grau de antropismo e desmatamento dos Estados inseridos na Caatinga, no período de 2008 a 2009 , tem como referência a área total original da Caatinga. A Caatinga paraibana possui $51.262 \mathrm{~km}^{2}$ do bioma remanescente e contêm $91,89 \mathrm{~km}^{2}$ de área antropizada. Confrontando com Giulietti et al. (2002), observa-se uma diferença de $2.262 \mathrm{~km}^{2}$ de abrangência da área de Caatinga. Essa divergência deve-se, provavelmente, à distância entre os anos das pesquisas e a metodologia utilizada para coleta dos dados.

Tabela 1 - Áreas das grandes unidades de paisagem que primitivamente incluíam vegetação de Caatinga na Paraíba

Table 1 - Areas of large landscape units that originally included Caatinga vegetation in Paraíba state

\begin{tabular}{lcc}
\hline Unidade de Paisagem & Área $\left(\mathbf{1 0}^{\mathbf{3}} \mathbf{~ m}^{\mathbf{2}}\right)$ & \% Caatinga \\
\hline Chapadas Altas & 0,10 & 0,20 \\
Planalto da Borborema & 12,40 & 25,30 \\
$\begin{array}{l}\text { Depressão Sertaneja } \\
\begin{array}{l}\text { Superfícies Dissecadas } \\
\text { Diversas }\end{array}\end{array}$ & 23,50 & 49,96 \\
$\begin{array}{l}\text { Maciços e Serras } \\
\text { Baixas }\end{array}$ & 6,70 & 9,60 \\
$\begin{array}{l}\text { Serrotes, Inselbergues e } \\
\text { Maciços Residuais }\end{array}$ & 1,40 & 14,08 \\
\hline Total & 49,00 & 2,86 \\
\hline
\end{tabular}

Fonte: Giulietti et al. (2002)

O Plano Estadual de Recursos Hídricos da Paraíba - PERH-PB de 2006 quantificou o uso do solo e a cobertura vegetal da Paraíba (Tabela 2). Os dados do PERH demonstram que cobertura vegetal da Caatinga no estado foi $31,56 \%\left(17.814 \mathrm{~km}^{2}\right)$, retirando as áreas que sofreram ação antrópica ou foram transformadas em áreas de preservação. Em todo o estado, o antropismo alcançou $63,0 \%$ da área total, ao passo que houve leve mudança do remanescente florestal. Isso não ocorreu em nível regional e local no interior do estado, mas em decorrência da existência de focos com alta extração de lenha e carvão vegetal. Em contrapartida, regiões com baixos níveis 
de antropização conseguiram conservar recursos naturais (PARAÍBA, 2006). Esse fenômeno foi mais detalhado observando a evolução do uso do solo segundo os censos agropecuários publicados pelo IBGE.

Tabela 2 - Uso do solo e cobertura vegetal do estado da Paraíba, em 2005

Table 2 - Land use and vegetation cover of the state of Paraíba, in 2005

\begin{tabular}{lcc}
\hline $\begin{array}{c}\text { Uso do Solo e Cobertura } \\
\text { Vegetal }\end{array}$ & Área $\left(\mathbf{k m}^{\mathbf{2}}\right)$ & \% Estadual \\
\hline $\begin{array}{l}\text { Caatinga Arbustiva } \\
\text { Arbórea Aberta }\end{array}$ & $10.375,00$ & 18,40 \\
$\begin{array}{l}\text { Caatinga Arbustiva } \\
\text { Arbórea Fechada }\end{array}$ & $6.127,00$ & 10,86 \\
$\begin{array}{l}\text { Caatinga Arbórea } \\
\text { Fechada }\end{array}$ & $1.312,00$ & \\
Restinga & 4,30 & 2,30 \\
Tabuleiros costeiros & 72,20 & 0,01 \\
Mangues & 98,50 & 0,12 \\
Mata Úmida & 51,70 & 0,17 \\
Mata Atlântica & 196,40 & 0,09 \\
Área de preservação & $1.148,00$ & 0,34 \\
permanente & 139,00 & 2,03 \\
Mata Semidecidual & $1.494,90$ & 0,23 \\
Outros & $35.420,00$ & 2,65 \\
Antropismo & $56.439,00$ & 100,00 \\
\hline Total & & \\
\hline
\end{tabular}

Fonte: Paraíba (2006)

\section{Tipos de uso do solo}

A Paraíba está dividida em quatro mesorregiões: o Agreste, a Borborema, o Sertão Paraibano e a Mata. A Caatinga abrange, principalmente, as três primeiras, somente a Mata Paraibana possui quase que exclusivamente o bioma Mata Atlântica. A Tabela 3 apresenta as áreas e a participação do uso do solo na Paraíba e no semiárido paraibano, para 1996, 2006 e 2017. A área de uso do solo estadual é de $5,47 \times 10^{6}$ ha e nota-se que as áreas de pastagens diminuíram gradativamente a um decrescimento médio de $2,7 \%$ a.a. no período em estudo. Saindo de $32,8 \%$ (1996) do uso do solo paraibano, passando por $29,8 \%$ (2006) e chegando a $20,1 \%$, ao passo que as pastagens no semiárido paraibano tiveram uma taxa média de -0,72\% a.a., sendo em $23,5 \%$ (1996) de ocupação do bioma, cresceu para $31,4 \%$ (2006) e caindo a $20,1 \%$. 


\section{Tabela 3 - Área e participação do uso do solo na Paraíba e no semiárido paraibano, para 1996, 2006 e 2017}

Table 3 - Areas and participation of land use in Paraíba and the semiarid region of Paraiba state, for 1996, 2006 e 2017

\begin{tabular}{|c|c|c|c|c|c|c|c|c|c|c|c|c|}
\hline \multirow{3}{*}{ Tipos } & \multicolumn{4}{|c|}{1996} & \multicolumn{4}{|c|}{2006} & \multicolumn{4}{|c|}{2017} \\
\hline & \multicolumn{2}{|c|}{ Paraíba } & \multicolumn{2}{|c|}{ Semiárido PB } & \multicolumn{2}{|c|}{ Paraíba } & \multicolumn{2}{|c|}{ Semiárido PB } & \multicolumn{2}{|c|}{ Paraíba } & \multicolumn{2}{|c|}{ Semiárido PB } \\
\hline & $\begin{array}{c}\text { Área } \\
\left(10^{3} \text { ha }\right)\end{array}$ & $\%$ & $\begin{array}{c}\text { Área } \\
\left(10^{3} \text { ha }\right)\end{array}$ & $\%$ & $\begin{array}{c}\text { Área } \\
\left(10^{3} \text { ha }\right)\end{array}$ & $\%$ & $\begin{array}{c}\text { Área } \\
\left(10^{3} \text { ha }\right)\end{array}$ & $\%$ & $\begin{array}{c}\text { Área } \\
\left(10^{3} \text { ha }\right)\end{array}$ & $\%$ & $\begin{array}{c}\text { Área } \\
\left(1^{3} \mathbf{h a}\right)\end{array}$ & $\%$ \\
\hline Pastagens & $1.851,9$ & 32,8 & $1.203,1$ & 23,5 & $1.680,7$ & 29,8 & $1.610,4$ & 31,4 & $1.041,6$ & 18,45 & $1.033,0$ & 20,1 \\
\hline Lavouras & 640,8 & 11,3 & 519,4 & 10,1 & 663,7 & 11,7 & 522,0 & 10,2 & 445,6 & 7,89 & 269,2 & 5,3 \\
\hline Matas / florestas & 691,9 & 12,2 & 410,4 & 8,0 & $1.173,2$ & 20,8 & $1.144,8$ & 22,3 & $1.698,0$ & 30,07 & $1.525,6$ & 29,8 \\
\hline Outros Usos & $2.462,2$ & 43,7 & $2.993,2$ & 58,4 & $2.129,2$ & 37,7 & $1.848,9$ & 36,1 & $2.461,6$ & 43,59 & $2.288,3$ & 44,7 \\
\hline Total & $5.646,8$ & 100,0 & $5.126,1$ & 100,0 & $5.646,8$ & 100,0 & $5.126,1$ & 100,0 & $5.646,8$ & 100,0 & $5.126,1$ & 100,0 \\
\hline
\end{tabular}

Fonte: Brasil (2011) e IBGE (1996; 2006; 2017)

Para as lavouras ocorreu uma leve queda de 1,71\% a.a., pois apresentavam uma área de $640,8 \times 10^{3}$ (1996) e chegou a $445,6 \times 10^{3}$ ha; no semiárido essa queda foi mais expressiva de $-3,08 \%$ a.a. As matas/florestas evidenciaram aumentos significativos tanto em termos estaduais (4,37\% a.a.), quanto em abrangência no semiárido paraibano (6,5\% a.a.), recompondo em 2017 cerca de $30 \%$ de ambas as áreas. Logo, durante o período, houve uma redistribuição do uso do solo entre pastagens, lavouras e outros usos às matas/florestas.Essa tendência, de forma mais acentuada, manteve-se nas mesorregiões doestado onde o bioma Caatinga impera (semiárido). Segundo o IBGE (2017), a região destinada à lavoura quase não modificou, enquanto a região de mata dobrou a sua área no período, um aumento de $734,4 \times 10^{3}$ ha. Essa evolução se deve às modificações de conjuntura econômica e o processo migratório da população do meio rural para o urbano. Observou que no início dos anos 1990 à 2000, a população rural decresceu 25\% frente à população total do estado da Paraíba. Em menor escala, durante o período estudado, também recebeu a presença dos programas sociais que ampliaram a capacidade de consumodas famílias de baixa renda (ex. o Bolsa Família).

A nova formação do uso do solo pode ser explicada pela transformação das áreas de pastagem, que diminuíram de importância ao longo dos dez anos do período. O crescimento das áreas ocupadas por matas/florestas se deve pela redução das áreas da agropecuária, as quais houve regeneração dos remanescentes florestais. Ressalta-se uma alteração clara no uso das terras do estado da Paraíba com uma ampliação, no total, da área de mata. No entanto, esse progresso não é devido às atitudes de reflorestamento ou a uma mitigação do desmatamento no estado. Resulta do abandono de terras de pastagens ou lavouras, onde aos poucos a vegetação nativa da Caatinga se regenera e volta a predominar nas áreas degradadas.

Na década de 1990, com a forte seca na região, a participação do setor agropecuário no PIB chegou a alcançar 5,8\%, em 1996, segundo dados do IBGE. Já na década de 2000, mais especificamente no período 2002-2010, o crescimento médio do PIB agropecuário paraibano foi de $0,9 \%$. O baixo dinamismo do Setor Agropecuário paraibano foi refletido em uma participação de apenas 4,2\% no PIB estadual, em 2010. Dentre os motivos para tal situação encontram-se a seca, a agricultura familiar, que é extremamente vulnerável a condições climáticas adversas, e a ampliação dos programas sociais para famílias de baixa renda (IBGE, 2017). 


\section{Estabelecimentos agropecuários}

A Tabela 4 apresenta a evolução da distribuição dos estabelecimentos agropecuários, quantidade $\left(\mathrm{x} 10^{3}\right)$ e área em milhões de hectares $\left(10^{6} \mathrm{ha}\right)$, na Paraíba e no semiárido paraibano, para 1996, 2006 e 2017. O estado da Paraíba possui área total de 5.646.843,5 ha e o bioma Caatinga paraibano de 5.126 .119 ha, com uma tendência da menor utilização do solo à agropecuária. No período de 1996 a 2017, a Paraíba apresentou crescimento médio de 0,47\% a.a. de estabelecimentos agropecuários. Já no semiárido paraibano, o crescimento foi mais expressivo,a taxa de 1,17\% a.a., com mais de 15 mil unidades. $\mathrm{Na}$ área dos estabelecimentos rurais do estado $(-0,86 \%$ a.a.) foi maior que no semiárido (-0,71\% a.a.), e proporcionou redução de 684,80 mil haestadual, alterando o uso do solo. Observou-se o desmembramento de grandes fazendas (áreas $>1.000$ ha) emnos estabelecimentos inferiores a 100 ha, principalmente, no semiárido paraibano. Somando os extratos de 0 a 10 ha e de 10 a 100 ha, em 1996, os estabelecimentos no semiárido correspondiam a $93,36 \%$ e, em 2017 , o grupo evoluiu para $95,84 \%$ (44,12\% em área), compondo um incremento de 164,6 mil ha.

\section{Tabela 4 - Evolução da distribuição por tamanho dos estabelecimentos agropecuários, quantidade $\left(\mathrm{x}_{10}\right)$ e área em milhões de hectares $\left(1^{6} \mathrm{ha}\right)$, na Paraíba e no semiárido paraibano, para 1996, 2006 e 2017}

Table 4 - Evolution of distribution by size of agricultural establishments, quantity $\left(\mathrm{x} 10^{3}\right)$ and area in millions hectares $\left(\mathrm{x} 10^{6} \mathrm{ha}\right)$, in Paraíba and the semi-arid region of Paraíba state, for

1996, 2006 and 2017

\begin{tabular}{|c|c|c|c|c|c|c|c|c|c|c|c|c|}
\hline \multirow{3}{*}{$\begin{array}{c}\text { Tamanhos } \\
\text { (ha) }\end{array}$} & \multicolumn{4}{|c|}{1996} & \multicolumn{4}{|c|}{2006} & \multicolumn{4}{|c|}{2017} \\
\hline & \multicolumn{2}{|c|}{ Paraíba } & \multicolumn{2}{|c|}{ Semiárido $\mathbf{P B}^{*}$} & \multicolumn{2}{|c|}{ Paraíba } & \multicolumn{2}{|c|}{ Semiárido PB } & \multicolumn{2}{|c|}{ Paraíba } & \multicolumn{2}{|c|}{$\begin{array}{c}\text { Semiárido } \\
\text { PB }\end{array}$} \\
\hline & 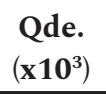 & $\begin{array}{l}\text { Área } \\
(\mathbf{x 1 0})\end{array}$ & $\begin{array}{l}\text { Qde. } \\
\left(\mathbf{x 1 0}^{3}\right)\end{array}$ & $\begin{array}{l}\text { Área } \\
\left(\mathbf{x 1 0 ^ { 6 }}\right)\end{array}$ & $\begin{array}{l}\text { Qde. } \\
\left(\mathbf{x} 10^{3}\right)\end{array}$ & $\begin{array}{l}\text { Área } \\
\left(\mathbf{x 1 0 ^ { 6 }}\right)\end{array}$ & $\begin{array}{l}\text { Qde. } \\
\left(\mathbf{x} 10^{3}\right)\end{array}$ & $\begin{array}{l}\text { Área } \\
(\mathbf{x 1 0})\end{array}$ & $\begin{array}{l}\text { Qde. } \\
\left(\mathbf{x} 10^{3}\right)\end{array}$ & $\begin{array}{c}\text { Área } \\
\left(\mathbf{x 1 0 ^ { 6 }}\right)\end{array}$ & $\begin{array}{l}\text { Qde. } \\
\left(\mathbf{x} 10^{3}\right)\end{array}$ & $\begin{array}{l}\text { Área } \\
\left(\mathbf{x} 10^{6}\right)\end{array}$ \\
\hline de 0 a 10 & 101,43 & 0,29 & 70,23 & 0,21 & 110,92 & 0,32 & 76,79 & 0,23 & 113,898 & 0,32 & 95,51 & 0,278 \\
\hline de 10 a 100 & 36,84 & 1,10 & 32,87 & 0,99 & 41,87 & 1,17 & 37,37 & 1,07 & 41,579 & 1,13 & 39,79 & 1,09 \\
\hline $\begin{array}{l}\text { de } 100 \mathrm{a} \\
1.000\end{array}$ & 7,76 & 1,96 & 6,96 & 1,75 & 6,92 & 1,70 & 6,21 & 1,53 & 5,927 & 1,47 & 5,67 & 1,39 \\
\hline$>1.000$ & 0,42 & 0,76 & 0,38 & 0,65 & 0,33 & 0,59 & 0,30 & 0,51 & 0,252 & 0,50 & 0,21 & 0,34 \\
\hline Total & 146,45 & 4,11 & 110,43 & 3,62 & 160,05 & 3,79 & 120,67 & 3,33 & 161,66 & 3,42 & 141,18 & 3,11 \\
\hline
\end{tabular}

Fonte: IBGE $(1996 ; 2006 ; 2017)$

Em que: *Valores estimados.

As áreas dos estabelecimentos com área superior a 100 ha, em 1996, representaram 66,6\% do semiárido e passaram a atingir 55,88\% (2017). Há fatores que colaboraram para a incomum formação de alguns resultados do Censo de 1996, 2006 e 2017, a exemplo das atividades não agrícolas que surgiram de forma acentuada e o êxodo rural. Não obstante, os programas sociais do governo federal contribuíram para que produtores de todas as idades de subsistência suspendessem suas atividades. Averiguou-se que houve mudança na distribuição de estabelecimentos agropecuários do estado da Paraíba desde 1996. Esta permanece concentrada, porém, em 1996, pois mais de $1.500 \times 10^{3}$ ha eram dos estabelecimentos com mais de 100 ha e controlavam mais da metade da área total (IBGE, 1996; 2006; 2017). Em 2017, essas proporções foram para outro caminho, 
em que os estabelecimentos com menos de 100 ha aumentaram e passaram a ter um valor mais significativo. No grupo de estabelecimentos com área entre 100 e 1.000 ha, registrou-se um declínio, porém esse grupo ainda detém a maior abrangência. A faixa das áreas maiores que 1.000 ha também diminuíram e se mantiveram em terceiro lugar de área de abrangência. As áreas cultivadas limitam as populações das espécies nativas e são capazes de causar um pequeno impacto negativo na região, como também ocasionar a destruição de muitas espécies. Isso se origina do local onde a diversidade está sendo analisada e da proporção da abrangência das áreas cultivadas, assim como do tamanho e distribuição das populações das espécies nativas que estão na área total. As áreas individuais cultivadas ou campos agrícolas formam um conjunto grande e distribuído inadequadamente pela região.

\section{Produção agropecuária e florestal}

De acordo com Paupitz (2010), o uso da terra no semiárido nordestino esteve historicamente relacionado à junção de duas atividades econômicas: a pecuária extensiva e a produção de algodão. A pecuária foi originalmente desenvolvida por grandes proprietários de terra, já a produção de algodão foi aliada a geração de renda para os pequenos produtores. Os dois casos estabeleceram a base do sistema de sustentação do modelo de ocupação da terra na Paraíba. A distribuição real e acurada da região da Caatinga, conforme literatura, é desconhecida, possuindo várias lacunas nos dados já coletados, e dificilmente está relacionada a divisão política dos municípios. A análise da área cultivada, por municípios, traz uma noção da cobertura vegetal do bioma.

A Tabela 5 apresenta os principais grupos de atividade econômica por área (ha), no semiárido paraibano, em 2017. A ocupação do solo no semiárido por meio das atividades agropecuárias é: lavoura temporária; horticultura e floricultura; lavoura permanente; sementes, mudas, etc.; pecuária e criação de outros animais; produção florestal oriundo de florestas plantadas; produção florestal oriundo de florestas nativas; pesca e aquicultura. O que chamou a atenção foi a proeminência da pecuária e criação de animais, com $50,7 \%$ da área total da Caatinga, concentrado nos estabelecimentos superiores a 100 ha, representando 60,24\% do rebanho. Percebeu-seque o grupo com menor participação foi o de sementes, mudas e outras formas de propagação vegetal de produtos agrícolas, com 49 ha de área. Apesar de não ter um valor representativo, é de responsabilidade dos estabelecimentos inferiores a 10 ha. Logo, essa atividade é de suma importância, visto que são os guardiões das sementes crioulas e essencial para agroecologia. As lavouras permanentes e temporárias abrangeram $7,11 \%$ da cobertura do bioma no estado e estão na segunda posição. Já as áreas de Produção florestal (nativa e plantada) ocuparam o terceiro lugar com 40.198 ha $(9,7 \%)$, que estão associados à lenha, carvão, estacas, moirões, postes e madeira. Estes fazem uso do extrativismo vegetal, geralmente, sem um manejo adequado às espécies arbóreas.

Apesar das consequências da abrangência de áreas voltadas para a agropecuária, várias áreas de pasto nativo do semiárido preservam uma boa cobertura de vegetação nativa. Essas áreas não foram queimadas, nem roçadas, e onde há antropização se restringe às atividades de pecuária e às pequenas coletas de produtos do extrativismo vegetal (GIULIETTI et al., 2004). A lenha é o produto predominantemente extraído da Caatinga, utilizada como combustível para comércio, indústrias e domicílios, como também para a produção de carvão. Outros produtos não-madeireiros são produzidos em escala menor, como: castanha de caju e os frutos do umbu e da mangaba (IBGE, 1996; 2006; 2017). 
Tabela 5 - Principais grupos de atividade econômica por área (ha), no semiárido paraibano, em 2017

Table 5 - Main groups of economic activity by area (ha,) in the semi-arid region of Paraíba state, in 2017

\begin{tabular}{lcccccc}
\hline \multicolumn{1}{c}{ Grupos } & $\mathbf{h a}<\mathbf{1 0}$ & $\mathbf{1 0} \leq \mathbf{h a}<\mathbf{1 0 0}$ & $\mathbf{1 0 0} \leq \mathbf{h a}<\mathbf{1 0 0 0}$ & $>\mathbf{1 0 0 0}$ ha & Total (ha) & Caatinga $(\mathbf{\%})$ \\
\hline $\begin{array}{l}\text { Lavoura } \\
\text { temporária }\end{array}$ & 84.902 & 177.667 & 101.754 & -0 & 364.323 & 7,11 \\
$\begin{array}{l}\text { Horticultura e } \\
\text { floricultura }\end{array}$ & 5.853 & 10.075 & 3.237 & - & 19.165 & 0,37 \\
$\begin{array}{l}\text { Lavoura } \\
\text { permanente }\end{array}$ & 13.462 & 14.546 & 9.133 & - & 37.141 & 0,72 \\
$\begin{array}{l}\text { Sementes, mudas, } \\
\text { etc. }\end{array}$ & 49 & - & - & - & 49 & - \\
$\begin{array}{l}\text { Pecuária e criação } \\
\text { out. animais }\end{array}$ & 164.853 & 868.530 & 1.255 .170 & 310.296 & 2.598 .849 & 50,70 \\
$\begin{array}{l}\text { Prod. florestal } \\
\text { (plantadas) }\end{array}$ & 708 & 2.746 & 3.175 & - & 6.629 & 0,13 \\
$\begin{array}{l}\text { Prod. florestal } \\
\text { (nativas) }\end{array}$ & 7.971 & 18.644 & 11.362 & 4542 & 42.519 & 0,83 \\
$\begin{array}{l}\text { Pesca } \\
\text { Aquicultura }\end{array}$ & 302 & - & - & - & 302 & 0,01 \\
\hline
\end{tabular}

Fonte: Adaptado de IBGE (2018)

Em que: ${ }^{1}$ Área da Caatinga $=5.126 .119$ ha.

A Tabela 6 apresenta a evolução da produção e do valor bruto de produção do extrativismo vegetal no estado da Paraíba, para 1995, 2000, 2005, 2010, 2015 e 2018. De maneira geral, os produtos do extrativismo vegetal foram decrescentes ao do período em análise, com exceção do fruto da mangaba. A lenha e o carvão vegetal foram os principais produtos do extrativismo vegetal da Paraíba, apesar da tendência de diminuição da produção, com exceção da madeira em toras, como foi observado por Coelho Junior et al. (2019a) nas mesorregiões da Paraíba. Entre 1996 e 2018, observou-se um grande aumento na produção de Mangaba (Hancornia speciosa, da família Apocynaceae). A produção de Umbu (Spondias tuberosa, da família Anacardiaceae) diminuiu, assim como houve uma redução do seu valor.

Dentre os produtos madeireiros do extrativismo vegetal, de 2000 a 2015 , não houve registros no IBGE da Madeira em toras, mas em 2018 atingiu um volume de $1.510 \mathrm{~m}^{3}$. O carvão vegetal $(-7,38 \%$ a.a.) e a lenha $(-2,34 \%$ a.a.) obtiveram drásticas queda de oferta no período estudado. Em 1995, a produção de lenha $\left(1\right.$ milhão $\left.\mathrm{m}^{3}\right)$ era cerca de duas vezes maior (581 mil $\left.\mathrm{m}^{3}\right)$ que em 2018, e a de carvão com redução de cerca de seis 6 vezes. Ndagijimana, Pareyn e Riegelhaupt (2015) afirmam da existência de dois cenários para a diminuição do consumo de madeira no estado da Paraíba. O primeiro cenário associado a uma redução por parte do setor industrial. E o segundo cenário apresentado seria da "estabilização do consumo", pressupondo que o consumo doméstico foi suprimido pelo Gás Liquefeito de Petróleo (GLP) e a o consumo industrial permaneceu estável. 
Tabela 6 - Evolução da produção e do valor bruto de produção do extrativismo vegetal no estado da Paraíba, para 1995, 2000, 2005, 2010, 2015 e 2018

Table 6 - Extractive production and value of production in the state of Paraíba (in current terms), for 1995, 2000, 2005, 2010, 2015 and 2018

\begin{tabular}{|c|c|c|c|c|c|c|c|c|c|c|c|c|}
\hline \multirow{2}{*}{ Produto } & \multicolumn{2}{|c|}{1995} & \multicolumn{2}{|c|}{2000} & \multicolumn{2}{|c|}{2005} & \multicolumn{2}{|c|}{2010} & \multicolumn{2}{|c|}{2015} & \multicolumn{2}{|c|}{2018} \\
\hline & Qde. & $10^{3} \mathrm{R} \$$ & Qde. & $10^{3} \mathrm{R} \$$ & Qde. & $10^{3} \mathrm{R} \$$ & Qde. & $10^{3} \mathrm{R} \$$ & Qde. & $10^{3} \mathrm{R} \$$ & Qde. & $10^{3} \mathrm{R} \$$ \\
\hline $\begin{array}{l}\text { Carvão } \\
\text { vegetal }(\mathbf{t})\end{array}$ & 5.397 & 677 & 3.536 & 529 & 1.792 & 488 & 1.163 & 597 & 735 & 727 & 925 & 878 \\
\hline Lenha $\left(\mathbf{m}^{3}\right)$ & 1.001 .023 & 3.027 & 855.574 & 3.824 & 653.772 & 3.655 & 589.082 & 5.785 & 495.625 & 10.968 & 581.226 & 13.256 \\
\hline $\begin{array}{l}\text { Madeira tora } \\
\left(\mathbf{m}^{3}\right)\end{array}$ & 3.700 & 21 & 1.673 & 43 & - & - & - & - & - & - & 1.510 & 156 \\
\hline $\begin{array}{l}\text { Alimentícios } \\
\text { (t) }\end{array}$ & 647 & 166 & 463 & 271 & 642 & 567 & 608 & 651 & 422 & 827 & 1.272 & 1.955 \\
\hline $\begin{array}{l}\text { Castanha- } \\
\text { de-caju }(\mathbf{t})\end{array}$ & 397 & 112 & 372 & 252 & 501 & 458 & 398 & 476 & 206 & 496 & 212 & 615 \\
\hline Mangaba (t) & 9 & 3 & - & - & 48 & 67 & 99 & 102 & 136 & 269 & 733 & 1.037 \\
\hline Umbu (t) & 241 & 51 & 90 & 19 & 92 & 42 & 111 & 73 & 80 & 62 & 227 & 203 \\
\hline Outros & $\ldots$ & $\ldots$ & $\ldots$ & $\ldots$ & $\ldots$ & $\ldots$ & $\ldots$ & $\ldots$ & - & - & 100 & 101 \\
\hline $\begin{array}{l}\text { Aromáticos* } \\
\text { (t) }\end{array}$ & - & - & - & - & - & - & - & - & - & - & - & - \\
\hline Borrachas (t) & - & - & - & - & - & - & - & - & - & - & - & - \\
\hline Ceras $(\mathbf{t})$ & 7 & 18 & 8 & 18 & 2 & 3 & - & - & - & - & 19 & 133 \\
\hline Fibras $(\mathbf{t})$ & - & - & - & - & - & - & - & - & - & - & - & - \\
\hline $\begin{array}{l}\text { Oleaginosos } \\
(\mathbf{t})\end{array}$ & 7.481 & 581 & - & - & - & - & - & - & - & - & - & - \\
\hline Tanantes $(t)$ & - & - & - & - & - & - & - & - & - & - & - & - \\
\hline
\end{tabular}

Fonte: IBGE (2019)

Em que: ... valor não disponível. *Aromáticos incluem medicinais, tóxicos e corantes.

\section{Áreas de remanescentes florestais}

A Tabela 7 expõe que o bioma Caatinga perdeu mais de $46 \%$ da sua vegetação até o ano de 2015, somando cerca de 2,40 milhões de hectares desmatados. No entanto, o processo do desmatamento aparenta ter desacelerado se comparado aos primeiros períodos, em que a taxa entre o período de 2002 e 2008 foi de $1,97 \%$ e entre 2008 e 2009 foi de $0,18 \%$. O volume do desmatamento diminuiu a partir de 2008 em relação aos seis anos passados. Ndagijimana, Pareyn e Riegelhaupt (2015) mostraram as consequências da otimização da fiscalização, da intensificação de planos de manejo, e/ou dos programas de combate ao desmatamento por órgãos 
governamentais. Além das ações específicas, a redução do desmatamento se explica também por alterações estruturais como, por exemplo, a atenuação do atrativo e a viabilidade econômica cada vez menor das atividades agropecuárias no semiárido, a fuga para a cidade e o abandono da atividade agrícola.

Tabela 7 - Desmatamento do bioma Caatinga na Paraíba

Table 7- Deforestation of the Caatinga biome in Paraíba state

\begin{tabular}{lccc}
\hline Período & Área desmatada & Desmatamento (\%) & Área desmatada* (\%) \\
\hline Até 2002 & $2.234 .284,00$ & - & 43,58 \\
$\mathbf{2 0 0 2 - 2 0 0 8}$ & $2.335 .602,00$ & 1,97 & 45,56 \\
$\mathbf{2 0 0 8 - 2 0 0 9}$ & $2.344 .791,00$ & 0,18 & 45,74 \\
$\mathbf{2 0 1 5 - 2 0 1 6}$ & $2.399 .925,00^{* *}$ & 0,18 & 46,82 \\
\hline
\end{tabular}

Fonte: Elaboração própria a partir de dados de Brasil (2011) e Ndagijimana, Pareyn e Riegelhaupt (2015)

Em que: *Área total de 5.126.119 ha. ${ }^{* *}$ Estimativa própria.

Com base na área remanescente do período de 2008 a 2009 e aplicando-se a mesma taxa de desmatamento de 0,18\% (9.189 ha/ano), calculou-se uma estimativa para o período 20152016. Se o desmatamento tivesse a mesma tendência durante os últimos anos de 2009 a 2016, aproximadamente 55 mil hectares teriam sido desmatados na Caatinga do estado, chegando a um total de 2,39 milhões de hectares de bioma suprimido, um percentual de 46,82\%. Sá et al. (2013) mostraram que aproximadamente $85 \%$ do semiárido paraibano apresenta-se na condição de sensibilidade à desertificação em que prevalece as classes de Acentuada e Severa, que juntas representam 4.188.037,68 ha. Conforme Brasil (2008), a Paraíba possui 5.126.119 ha do bioma Caatinga no estado. Menos de $0,05 \%$ da superfície do bioma é protegido por apenas seis Unidades de Conservação de Proteção Integral, onde não é permitida a prática do manejo florestal. Existem ainda oito Unidades de Uso Sustentável, que juntas somam menos de $2 \%$ da superfície da Caatinga e é possível a prática do manejo florestal (Tabela 8).

Tabela 8 - Unidades de Conservação no bioma Caatinga no estado da Paraíba

Table 8 - Conservation Units in the Caatinga biome in the state of Paraíba

\begin{tabular}{|c|c|c|c|c|c|}
\hline Administração & Grupo & Categoria & Nome & Área (ha) & Caatinga $(\%)$ \\
\hline \multirow{6}{*}{ Estadual } & \multirow{6}{*}{ PI } & \multirow[b]{2}{*}{ REBIO } & $\begin{array}{l}\text { Reserva Ecológica } \\
\text { Mata do Pau Ferro }\end{array}$ & 600 & 0,01 \\
\hline & & & $\begin{array}{c}\text { Reserva Ecológica } \\
\text { Mata de } \\
\text { Goiamunduba }\end{array}$ & 67 & 0,00 \\
\hline & & \multirow{3}{*}{ Parque } & Parque dos Poetas & 419 & 0,01 \\
\hline & & & Pedra da Boca & 157 & 0,00 \\
\hline & & & Pico do Jabre & 851 & 0,02 \\
\hline & & $\mathrm{MN}$ & $\begin{array}{c}\text { Vale dos } \\
\text { Dinossauros }\end{array}$ & 40 & 0,00 \\
\hline \multicolumn{4}{|c|}{ Total de Unidades de conservação de proteção integral na Paraíba } & 2.135 & 0,04 \\
\hline
\end{tabular}


Tabela 8 - Conclusão ...

Table 8 - Conclusion ...

\begin{tabular}{|c|c|c|c|c|c|}
\hline Administração & Grupo & Categoria & Nome & Área (ha) & Caatinga $(\%)$ \\
\hline \multirow{2}{*}{ Estadual } & \multirow{2}{*}{ US } & \multirow{2}{*}{ APA } & do Cariri & 18.560 & 0,36 \\
\hline & & & das Onças & 36.000 & 0,70 \\
\hline \multicolumn{4}{|c|}{ Total de Unidades de conservação de uso sustentável } & 54.560 & 1,06 \\
\hline \multirow{6}{*}{ Privada } & \multirow{6}{*}{ US } & \multirow{6}{*}{ RPPN } & Fazenda Almas & 3.505 & 0,07 \\
\hline & & & $\begin{array}{c}\text { Fazenda Pedra de } \\
\text { Água }\end{array}$ & 170 & 0,00 \\
\hline & & & $\begin{array}{c}\text { Fazenda Santa } \\
\text { Clara }\end{array}$ & 751 & 0,01 \\
\hline & & & Fazenda Tamanduá & 325 & 0,01 \\
\hline & & & Fazenda Várzea & 391 & 0,01 \\
\hline & & & $\begin{array}{c}\text { Major Badú } \\
\text { Loureiro }\end{array}$ & 186 & 0,00 \\
\hline \multicolumn{4}{|c|}{ Total de Reservas Particulares do Patrimônio Natural na Paraíba } & 5.327 & 0,10 \\
\hline \multicolumn{4}{|c|}{ Total de Unidades de Conservação } & 62.022 & 1,21 \\
\hline
\end{tabular}

Fonte: Adaptado de Brasil (2008)

Em que: $\mathrm{PI}=$ Proteção integral; US = Uso sustentável; REBIO = Reserva biológica; $\mathrm{MN}=$ Monumento natural; APA = Área de proteção ambiental; RPPN = Reserva particular do patrimônio natural.

\section{Manejo florestal na Caatinga paraibana}

A exploração da Caatinga aconteceu por meio de três ações. A primeira pelo desmatamento legal para fins de uso alternativo do solo, como atividades agrícolas; a segunda por meio do manejo florestal sustentável, também autorizado pelos órgãos competentes, destinado a produção madeireira; e a terceira pelo desmatamento ilegal, objetivando o uso alternativo do solo e/ou a produção madeireira. A técnica do manejo florestal sustentado diminui as consequências do modelo extrativista predatório e sua importância para preservar o bioma como um todo. A Tabela 9 apresenta o quantitativo de Planos de Manejo Florestal Sustentado na Caatinga no estado da Paraíba, em 2012. Foram observados 57 planos de manejo protocolados, somente 1 plano está arquivado, 4 suspensos e 7 cancelados. Apresentavam-se 13 em análise e os 32 restantes autorizados. 
Tabela 9 - Distribuição dos planos de manejo florestal sustentável na Paraíba, em 2014

Table 9 - Distribution of sustainable forest management plans in Paraíba state, in 2014

\begin{tabular}{lcccc}
\hline \multicolumn{1}{c}{ Situação } & Quantidade & Área $(\mathbf{h a})$ & Volume $\left(\mathbf{m}^{\mathbf{3}} / \mathbf{h a}\right)$ & Tipo de produto \\
\hline Arquivado & 1 & 356 & 79,87 & \\
Ativos & 32 & 12.754 & $1.453,79$ & \\
Cancelado & 7 & 3.020 & 621,74 & Lenha e carvão \\
Em análise & 13 & 4.476 & $1.036,47$ & \\
Suspenso & 4 & 2.071 & 231,91 & \\
\hline Total & 57 & 22.677 & $3.423,78$ & - \\
\hline
\end{tabular}

Fonte: Adaptado de Associação Plantas do Nordeste (2017)

As áreas dos planos autorizados de manejo florestal sustentável equivalem aproximadamente 13 mil ha. Porém, se todos os PMFS estivessem ativos seria de mais de 22 mil ha, ou seja, 56,24\% dos PMFS apresentados estavam realmente ativos. A Associação Plantas do Nordeste (2017) atualizou os PMFS ativos para em termos de quantidade de ativos e suas áreas, impossibilitando uma análise mais completa e comparativa com os PMFS em outras situações e volumes produzidos por hectare. Os valores informados foram de 35 ativos e 14.262 ha de área de manejo (APNE, 2015). Para Giulietti et al. (2002), a lenha foi o mais explorado da Caatinga paraibana e o carvão vegetal (19 $\mathrm{m}^{3}$ de lenha produzem 1 tonelada de carvão vegetal). Ensaios recentes de CoelhoJunior, Burgos e Santos Junior (2018) e Coelho Junior et al. (2019b) buscaram entender o comportamento da produção desses dois produtos do extrativismo vegetal da Paraíba que encontram-se no semiárido paraibano.

No intuito de uma estimativa do impacto da produção de lenha e carvão sobre as áreas que utilizam o PMFS, a Tabela 10 confronta os dados dos PMFS ativos (Tabela 10) com os da produção de lenha e carvão, tentando assim analisar as áreas com maior necessidade a um PMFS. Para cálculo do valor de percentual de Caatinga foi adotado 5.126.119 ha de área total de Caatinga na PB. A oferta do manejo florestal sustentável atinge apenas $0,01 \%$ da demanda total de $0,14 \%$. Observase que a soma das áreas utilizadas para produção anual de lenha e de carvão é de $7.280,36$ ha e somente 918,00 ha possuem PMFS ativos. A área necessária para atender a demanda sustentável precisaria aumentar sete vezes. Torna-se preocupante a pequena participação das áreas de manejo florestal numa década em que todos os programas e convenções internacionais firmam o uso de alternativas mais sustentáveis como caminho indispensável para o desenvolvimento.

\section{Tabela 10 - Áreas com maior necessidade de um plano de manejo florestal sustentável (PMFS) na Paraíba}

Table 10 - Areas with the greatest need for a sustainable forest management plan in Paraíba state

\begin{tabular}{lcc}
\hline & Área (ha a.a.) & \% Caatinga \\
\hline Lenha & $7.080,36$ & 0,14 \\
Carvão & 199,50 & 0,00 \\
PMFS ativos & 918,00 & 0,01 \\
\hline
\end{tabular}

Fonte: Associação Plantas do Nordeste (2015) 
Na Tabela 11, observa-se o conjunto de informações obtidas para caracterizar a situação atual da área de Caatinga no estado da Paraíba. O Estado, por meio dos seus órgãos competentes, se restringe às autorizações do manejo e à fiscalização do consumo dos produtos florestais. As condições disponíveis no órgão estadual de meio ambiente (Superintendência do Meio Ambiente - SUDEMA) são incapazes de atender a demanda do setor florestal. Existe também um determinado descontrole e falta de levantamento de dados, visto que o consumo ilegal excede a oferta legal. No entanto, não há qualquer atitude, além de folhetos e eventuais participações em fóruns nacionais, para o incremento do manejo florestal sustentável por parte dos órgãos estaduais.

Tabela 11 - Situação atual da distribuição da área de Caatinga na Paraíba

Table 11 - Current situation of the distribution of the Caatinga area in Paraíba

\begin{tabular}{lcc}
\hline & Área $($ ha) & \% Caatinga \\
\hline PMFS ativos & $12.754,00$ & 0,25 \\
$\begin{array}{l}\text { Unidades de } \\
\text { Conservação }\end{array}$ & $62.022,00$ & 1,21 \\
Desmatamento & $2.344 .791,00$ & 45,66 \\
Área remanescente & $1.272 .283,60$ & 24,82 \\
\hline
\end{tabular}

Fonte: APNE (2015)

Para uma melhor visualização da evolução dos PMFS no bioma Caatinga e na Paraíba, foi levantado o número de pedidos de PMFS e a área de manejo (Figura 1). Houve um aumento da aplicação de PMFS em todo o bioma Caatinga, inclusive, na Paraíba. Observou-se que de 1999 a 2003 há uma ascensão no número de PMFS solicitados, porém a área de manejo não seguiu essa mesma tendência. Atribui-se isso ao fato de um conjunto de empreendimentos com áreas menores a serem manejadas terem entrado com o PMFS em um mesmo período. Em 2004 não houve pedido de PMFS e a partir de 2005 percebeu um aumento de pedidos e de área manejada até 2009 , em 2010 ocorre um decréscimo, todavia se mantendo ainda alto. Em 2011, o maior pico dentro do período estudado (1998-2012), atingindo 10 PMFS com área somada de 6.562,04 ha manejados.

Deve-se salientar que essa evolução foi referente aos pedidos de PMFS, ou seja, os protocolados e nem todos se mantiveram ou permaneceram em atividade, aumentando os PMFS na Paraíba trazendo benefícios para os produtores rurais, consumidores e para o Estado, favorecendo um melhor desempenho da gestão florestal mais sustentável. Quase todo o conjunto de florestas pertence aos proprietários privados e a despolarização da gestão florestal, associada à precariedade institucional dos órgãos governamentais, se mostra como proveitoso já que a responsabilidade de sustentar ou manejar essas florestas é dos proprietários. Isso também possibilitou que haja uma contribuição social maior das florestas nativas. Na situação especial da Caatinga, a introdução das matas nativas nos sistemas produtivos tradicionais beneficia a administração de uma área florestal nas propriedades rurais. Entretanto, a região do bioma tem a necessidade de uma conscientização florestal, de forma que a produção florestal se torne uma atividade produtiva séria e digna de um planejamento organizado. 
Figura 1 - Evolução dos PMFS e áreas de manejo autorizado na Paraíba, no período de 1998 a 2012

Figure 1 -Evolution of the PMFS and authorized management areas in Paraíba state, from 1998 to 2012

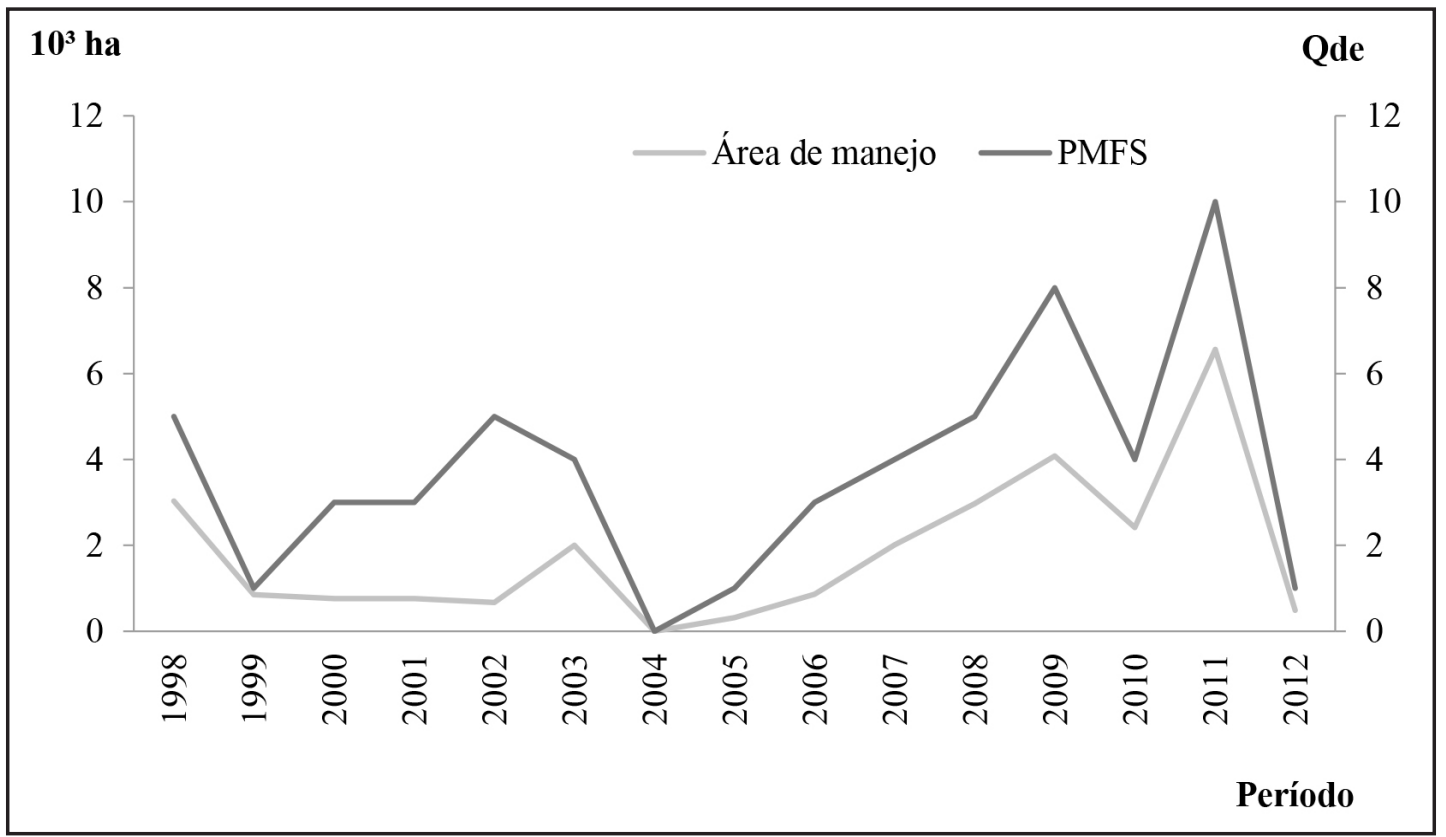

Fonte: Associação Plantas do Nordeste (2017)

\section{Conclusão}

Diante das análises realizadas, conclui-se que houve uma alteração no uso das terras da Paraíba com uma ampliação das áreas de matas/florestas e redução das áreas de pastagem, entre 1996 e 2018 .O carvão vegetal e a lenha do extrativismo vegetal obtiveram drásticas reduções de oferta no período estudado. A Caatinga paraibana perdeu mais de $46 \%$ da sua vegetação, cerca de 2,40 milhões de hectares, mas observou-se o aumento do PMFS na região do semiárido paraibano via adoção de políticas públicas e de conscientização do mercado. Às estimativas adotadas da cobertura vegetal e do uso do solo da Paraíba mostraram sensibilidade à desertificação do bioma, necessitando de ações conjuntas permanentes de restauração da vegetação original e que garantam o uso sustentável da biodiversidade. Conclui-se que a solução efetiva vem da conscientização e da prática do Plano de Manejo Florestal Sustentado no semiárido paraibano, proporcionando de forma mais eficaz a sustentabilidade do bioma Caatinga.

\section{Referências}

AHRENS, S. Sobre o manejo florestal sustentável de uso múltiplo: proteger a fauna para conservar as florestas. Revista de Direitos Difusos, São Paulo, v. 29, p. 61-76, jan./fev. 2005.

APNE - ASSOCIAÇÃO PLANTAS DO NORDESTE. Estatística Florestal da Caatinga. Recife, 2015. v. 2. 
APNE -ASSOCIAÇÃO PLANTAS DO NORDESTE.Planos de manejo florestal sustentado na caatinga. Recife, 2017. Disponível em: http://www.cnip.org.br/planos_manejo.html. Acesso em: 26 jul. 2017.

BARBOSA, M. R. V. et al. Estratégias para conservação da biodiversidade e prioridades para a pesquisa científica no bioma Caatinga. In: ARAUJO, F. S.; RODAL, M. J. N.; BARBOSA, M. R. V. (ed.). Análise das variações da biodiversidade do bioma Caatinga: suporte a estratégias regionais de conservação. Brasília, DF: Ministério do Meio Ambiente, p.415-432,2005.

BRASIL. Ministério do Meio Ambiente. Monitoramento dos biomas brasileiros - Caatinga 2008-2009. Brasília, 2011.

BRASIL. Ministério do Meio Ambiente. Secretaria de Recursos Hídricos. Programa de ação nacional de combate à desertificação e mitigação dos efeitos da seca PAN-BRASIL. Brasília, 2004. Disponível em: http://www.mma.gov.br/estruturas/sedr_desertif/_arquivos/pan_brasil_ portugues.pdf. Acesso em: 27 jul. 2017.

BRASIL. Ministério do Meio Ambiente. Unidades de conservação e terras indígenas do bioma caatinga. Brasília, 2008. Disponível em: http://www.mma.gov.br/estruturas/203/_arquivos/mapa_ das_ucs.pdf. Acessado em: 05 ago. 2017.

CASTELLETTI, C. H. M. et al. Quanto ainda resta da Caatinga? uma estimativa preliminar. In: SILVA, J. M. C. et al. (eds.). Biodiversidade da Caatinga: áreas e ações prioritárias para a conservação. Brasília, DF: Ministério do Meio Ambiente; Universidade Federal de Pernambuco, 2004.

COELHO JUNIOR, L. M.; BURGOS, M. C.; SANTOS JUNIOR, E. P. Concentração regional da produção de lenha da Paraíba. CiênciaFlorestal, Santa Maria, v. 28, p. 1729-1740, 2018.

COELHO JUNIOR, L. M. etal.Disparity of the gross value of production of the native wood products of the Paraíba mesoregions, Brazil (1994-2017). RevistaÁrvore, Viçosa, MG, v. 43, p. e430303, 2019a.

COELHO JUNIOR, L. M. etal.Regional concentration of charcoal production in Paraíba state, Brazil (1994-2016). RevistaÁrvore, Viçosa, MG, v. 43, p. e430105, 2019b.

COELHO JUNIOR, L. M.; MARTINS, K. L. C.; CARVALHO, M. Carbon Footprint Associated with Firewood Consumption in Northeast Brazil: An Analysis by the IPCC 2013 GWP 100y Criterion. Waste and Biomass Valorization, [s. l.], p. 1-9, 2018.

COELHO JUNIOR, L. M.; MARTINS, K. L. C.; SILVA, M. V. B. Spatial convergence of the gross value of production of firewood in the mesoregions of the Brazilian Northeast. Revista Árvore, Viçosa, MG, v. 42, p. e420203, 2018.

GARIGLIO, M. A.; BARCELlOS, N. D. E.Manejo florestal sustentável em assentamentos rurais na Caatinga - estudo de caso na Paraíba e Pernambuco. In: GARIGLIO, M. A. et al. Uso sustentável e conservação dos recursos florestais da Caatinga. Brasília: Serviço Florestal Brasileiro, p. 116 - 2017, 2010.

GIUliETTI, A. M. et al. Diagnóstico da vegetação nativa do bioma Caatinga.In: CARDOSO, J. M. S. et al. Biodiversidade da Caatinga: áreas e ações prioritárias para a conservação. Recife: APNE, p. 15 -27, 2003.

GIULIETTI, A. M. et al. Espécies endêmicas da Caatinga. In: SAMPAIO, E. V. S. B.; GIULIETTI, A. M.; GAMARRA-ROJAS, C. (org.). Vegetação e flora da Caatinga. Recife: APNE, p. 37 - 49, 2002.

IBGE.Censo agropecuário 2006. Rio de Janeiro, 2006. Disponível em: http://www.ibge.gov.br/ estadosat/temas.php?sigla=pb\&tema=censoagro. Acesso em: 26 jul. 2017.

IBGE.Censo agropecuário 2017. Rio de Janeiro, 2017. Disponível em: https://sidra.ibge.gov.br/ 
pesquisa/censo-agropecuario/censo-agropecuario-2017. Acesso em: 10 fev. 2020.

IBGE.Censo agropecuário do Brasil 1996. Rio de Janeiro, 1996. Disponível em: http://www. sidra.ibge.gov.br. Acesso em: 05 ago. 2017.

IBGE.Perfil Paraíba. Rio de Janeiro, 2016. Disponível em: http://www.ibge.gov.br/estadosat/ perfil.php?sigla=pb. Acesso em: 26 jul. 2017.

IBGE.Produçãoda extração vegetal e da silvicultura - PEVS. Rio de Janeiro, 2004. Disponível em: https://sidra.ibge.gov.br/pesquisa/pevs/quadros/brasil/2004. Acesso em: 25 jan. 2018.

IBGE.Produçãoda extração vegetal e da silvicultura - PEVS. Rio de Janeiro, 2018. Disponível em: https://sidra.ibge.gov.br/pesquisa/pevs/quadros/brasil/2016. Acesso em: 25 abr. 2018.

IBGE.Produçãoda extração vegetal e da silvicultura - PEVS. Rio de Janeiro, 2019. Disponível em: https://sidra.ibge.gov.br/pesquisa/pevs/quadros/brasil/2019. Acesso em: 17 set. 2019.

LEAL, I. R. et al.Mudando o curso da conservação da biodiversidade na Caatinga do Nordeste do Brasil. Megadiversidade, [s. l.], v. 1, n. 1, p. 139-146, 2005. Disponível em: https://portais.ufg.br/ up/160/o/19_Leal_et_al.pdf. Acesso em: 27 jul. 2017.

MARTINS, K. L. C. et al. Plant extractivism production disparity between Northeast Brazil and Brazil. Floram, [s. l.], v. 25, p. e20160456, 2018.

MELO, J. A. T. A agenda 21, o semiárido e a luta contra a desertificação. Brasília: MMA, 2004. 13 p. (Cadernos de debate Agenda 21 e sustentabilidade)

NDAGIJIMANA, C.; PAREYN, F. G. C.; RIEGELHAUPT, E. Uso do solo e desmatamento da caatinga: um estudo de caso na Paraíba e no Ceará - Brasil. In: BRASIL. Ministério do Meio Ambiente. Estatística Florestal da Caatinga. Recife, p. 18 - 29, 2015.

PARAÍBA. Plano Estadual de Recursos Hídricos da Paraíba. João Pessoa,2006. Disponível em: http://www.aesa.pb.gov.br/aesa-website/documentos/plano-estadual/resumo-estendido/. Acesso em: 05 ago. 2017.

PAUPITZ, J. Elementos da estrutura fundiária e uso da terra no semi-árido brasileiro. In: GARIGLIO, M. A. et al (org.). Uso sustentável e conservação dos recursos florestais da caatinga. Brasília: Serviço Florestal Brasileiro, 2010. p. 49 -64, 2010.

RIEGELHAUPT, E. M.; PAREYN, F. G. C. A Questão Energética. In: GARIGLIO, M. A. et al (org.). Uso sustentável e conservação dos recursos florestais da caatinga. Brasília: Serviço Florestal Brasileiro, p. 65 - 75, 2010.

SÁ, I. B. et al. Mapeamento da desertificação do semiárido paraibano com base na sua cobertura vegetal e classes de solos. In: SIMPÓSIO BRASILEIRO DE SENSORIAMENTO REMOTO, 16., Foz do Iguaçu. Anais [...].Foz do Iguaçu: S.B.S.R., p. 3112 - 3118, 2013.

SILVA, J. P. F.; SOARES, D. G.; PAREYN, F. G. C. Manejo Florestal da Caatinga: uma alternativa de desenvolvimento sustentável em projetos de assentamentos rurais do semi-árido em Pernambuco. In: BRASIL. Ministério do Meio Ambiente. Estatística Florestal da Caatinga. Natal, p. 6 - 17, 2008.

SCHUMACHER, M. V.; POGGIANI, F. Produção de biomassa e remoção de nutrientes em povoamentos de EucalyptuscamaldulensisDEHNH, EucalyptusgrandisHILLexMAIDEN e Eucalyptustorelliana f. MUELL, plantados em Anhembí, SP. Ciência Florestal, Santa Maria, v. 3, n. 1, p. 9-18, jan./abr. 1993. 